\title{
Análise fatorial do Questionário de Estilos Parentais (PAQ) em uma amostra de adultos jovens universitários
}

\author{
Mariana Gonçalves Boeckell \\ Jorge Castellá Sarriera
}

\begin{abstract}
Resumo
O objetivo deste estudo é investigar a estrutura fatorial do Questionário de Estilos Parentais (PAQ) desenvolvido por John Buri. A amostra estratificada foi composta por 323 estudantes de ambos os sexos que cursam uma universidade particular. Foi utilizada a análise de componentes principais, com rotação oblimin, empregando a regra de Kaiser (retenção dos autovalores maiores que 1). A análise demonstrou a presença de três fatores com autovalores superiores a 1. O total dos fatores explica $43,96 \%$ da variância total do construto estilos parentais. O primeiro fator explica 25,70\%; o segundo, 11,77\%; e o terceiro, $6,49 \%$. Os três fatores alcançaram um nível de consistência interna satisfatório. Os resultados sugerem possibilidades positivas de aplicação do instrumento em nossa realidade, mas faz-se necessário o desenvolvimento de futuros estudos sobre o instrumento em amostras diversificadas.

Palavras-Chave: Estilos parentais; Estratégias educacionais; Análise fatorial; Questionário de Estilos Parentais (PAQ).
\end{abstract}

\section{The factorial analysis of Parental Authoritative Questionnaire in a sample of college young adults}

\begin{abstract}
The aim of this study was to investigate the factorial structure of the Parental Authoritative Questionnaire (PAQ) elaborated by John Buri. The stratified sample was composed of 323 male and female private university students. It was used principal components analysis, with oblimin rotation, using the Kaiser rule (retention of eigenvalues higher than 1). The analysis showed tree factors with eigenvalues superior than 1 . The total of the factors explains $43,96 \%$ of the total variance about the parental style construct. The first factor explains $25,70 \%$, the second one, $11,77 \%$ and the third one, $6,49 \%$. The tree factors had satisfactory internal consistence. The results suggests positive measure's applications on our reality, but it is necessary the development of future studies concerning this questionnaire in diversified samples.

Keywords: Parental styles; Young adults; Factorial analysis; Parental Authoritative Questionnaire (PAQ).
\end{abstract}

\section{Introdução}

Quando falamos em estilos parentais, torna-se imprescindível falarmos de contexto familiar, desenvolvimento humano e socialização. Partindo do desenvolvimento humano desejado, o microssistema familiar tem como uma de suas funções primordiais ser o primeiro ambiente de socialização dos seus membros. A sociedade espera que a família possa preparar seus filhos para a convivência social. Será tarefa fundamental da família, então, proporcionar o desenvolvimento físico e emocional, assim como a independência de seus membros (Baumrind, 1980, 1996; Lane, 1999; Musito \& Cava, 2001; Ruiz \& Esteban, 1999). Essa função se dá a partir de algumas atitudes que são assumidas com exclusividade pela família, e outras são realizadas pelas demais instituições sociais. As atitudes e ações socializadoras e de aprendizagem da família referem-se principalmente a: cuidados físicos, relações interpessoais, formação de vínculos, atividades lúdicas, inserção escolar e social, atividades produtivas (Lane, 1999). Reis (1999) salienta que a maneira como o processo socializador se desenvolve ocorre a partir da permissividade ou da rigidez dos pais, estando associada ao modelo cultural de valores e de personalidade e influenciando na forma como é conduzida a dinâmica familiar. É a família a mediadora entre o individual e o social. É nela que aprendemos a perceber o nosso meio social e o modo como nos colocamos nele. Socialização é um processo de início para o mundo adulto, no qual cada pessoa adquire amadurecimento por meio da educação, treinamento e imitação, assim como por intermédio dos hábitos e dos valores congruentes com a adaptação à cultura. A organização familiar delimita e qualifica as experiências vivenciadas pelos membros que a compõem (Baumrind, 1980; Minuchin \& Nichols, 1982; Reis, 1999). Valendo-se de diversos mecanismos, tais como estilos educativos, transmissão, e valores e crenças, a família vai modulando as características do indivíduo (Musito \& Cava, 2001; Ruiz \& Esteban, 1999).

\footnotetext{
${ }^{1}$ Apoio da agência financiadora CAPES.

Endereço para correspondência:

E-mail: boeckel@brturbo.com.br
} 
A família tem um poder absoluto e, ao mesmo tempo, indefinido sobre a criança, já que certas características podem estar definidas ao nascer, assim como podem existir outros contextos que influem de forma paralela à educação oferecida pela família e, por último, porque a própria família é influenciada por diversos fatores que condicionam e determinam o funcionamento dos filhos (situação econômica, social, política, cultural) (Belsky, 1984; Ruiz \& Esteban, 1999).

De acordo com Baumrind (1971, 1978, 1980, 1996), os pais cuidadores desempenham um papel fundamental no desenvolvimento da criança. A carência de disciplina dos pais pode trazer insegurança à criança no que toca ao amor parental; por outro lado, os pais que não conseguem sentir um amor saudável por seus filhos não terão sucesso no controle destes.

Os pais ensinam a seus filhos como se relacionar com os outros, de quem gostar e não gostar, quem evitar e depreciar, como expressar amor e ressentimento, e também como e quando reprimir seus sentimentos e atitudes. A criança, por perceber a si por intermédio dos olhos de seus pais, aprende a perceber suas próprias características e valores. Mais tarde, sua auto-imagem é acrescentada e/ou alterada pelas atitudes para com os outros adultos e/ou outras crianças (Baumrind, 1965, 1996; Buri, Murphy, Richtsmeier \& Komar, 1988).

Baumrind (1965) diferencia três tipos de estilos parentais, os quais permeiam as atitudes dos pais para com os filhos: estilo autoritário, estilo permissivo e estilo autorizante. ${ }^{2}$

O estilo autoritário é contextualizado partindo do pressuposto de que os pais deveriam manter ordem dentro da família. Tal crença tem por base a tradição cultural e religiosa. Os pais autoritários acreditam em medidas calcadas na obediência como virtude, em fatores punitivos, em medidas de força.

No que tange ao estilo permissivo, Baumrind (1965) refere à crença naturalista, a qual tinha como ponto fundamental a idéia de que criança possui disposição natural à socialização; dessa forma, deveria deixá-la aprender por si só, assim como expressar sua capacidade para auto-atualização. $\mathrm{O}$ adulto permissivo parte de uma postura afirmativa, de aceitação. Os pais vêem a si como um recurso para a criança utilizar quando desejar, mas não como um agente ativo e responsável por ensinar e alterar os caminhos e comportamentos futuros da criança.

Finalmente, o estilo autorizante refere-se à idéia de que o cuidador não precisa decidir entre uma disciplina autoritária e permissiva, podendo alternar suas atitudes entre as duas contribuições. Os pais autorizantes encorajam as verbalizações, dividem com os filhos as

\footnotetext{
2Será utilizada a palavra "autorizante" para a tradução do inglês authoritative.
}

razões por trás do policiamento parental, dão espaço para argumentações. As atitudes autônomas e disciplinadas são valorizadas (Baumrind, 1965).

Além disso, o controle, o afeto e o apoio são importantes funções parentais, as quais impregnam as estratégias educacionais. A sinergia e integração dessas funções evidenciam o estilo autorizante, percebido por filhos e pais como manifestação de amor parental (Baumrind, 1965, 1978).

Pinderhughes, Dudge, Bates, Pettit e Zelli (2000) identificaram como resultados em sua investigação que pais com nível socioeconômico mais baixo tendem a utilizar disciplinas mais rígidas. $O$ alto índice de estresse estava relacionado com a elevada percepção negativa dos pais para com os filhos. As crenças parentais referentes à punição física e ao estresse se apresentaram como mediadoras de uma relação entre situação socioeconômica e estratégias disciplinares. Por outro lado, a percepção dos filhos mostrou ser mediadora do efeito do estresse nas atividades disciplinares parentais. Percebe-se a relevância da cultura e do contexto nas especificidades das atitudes educativas (Belsky, 1984).

Thompson, Raynor, Cornah, Stevenson e Sonuga-Barke (2001) salientam que a inconsistência parental, mais do que os métodos punitivos físicos, demonstrou ser um fator importante no desenvolvimento de problemas. Ademais, o clima emocional que permeia as respostas parentais é identificado como aspecto relevante na relação com os filhos (Thompson et al., 2001).

As estratégias educacionais podem ser avaliadas partindo da utilização de diversas possibilidades metodológicas, desde perspectivas quantitativas até qualitativas. Em termos quantitativos, várias medidas têm sido utilizadas, das quais podemos destacar dentre as mais empregadas: Parental Bonding Instrument (Melis, Dávila, Ormeño, Vera, Greppi \& Gloger, 2001; Reti, Samuels, Eaton, Bienvenu, Costa Jr. \& Nestadt, 2002), Escalas de Responsividade e Exigência (Costa, Gomes \& Teixeira, 2000; Oliveira, Marin, Pires, Frizzo, Ravanello \& Rossolo, 2002; Pacheco, Teixeira \& Gomes, 1999), Questionário de Estilos Parentais (Parental Authoritative Questionnaire - PAQ) (Buri, 1991). O presente artigo baseou-se no PAQ, tendo em conta ser este um instrumento fundamentado na perspectiva teórica de Baumrind (1996) e estar sendo utilizado de forma significativa internacionalmente (Bersabé, Fuentes \& Motrico, 2001; Buri, 1991; Furnham \& Cheng, 2000; Gonzáles, Greenwood \& WenHsu, 2001; Henderson, 2001; Lai \& McBride, 2001; Reitman, Rhode, Hupp \& Altobello, 2002; Wintre \& Sugar, 2000). No entanto, no Brasil, percebe-se a escassa produção científica referente à utilização deste instrumento.

Buri (1991), em seu estudo para formulação do $\mathrm{PAQ}$, realizou teste de confiabilidade, de consistência 
interna e análise de correlações entre as três subescalas que compunham o instrumento. Dentre essas correlações, percebeu a existência de correlação inversa existente entre estilo parental autoritário e autorizante.

Como visto, diversos estudiosos dedicaram-se a elaborar questionários sobre os estilos educativos parentais. Holden e Edwards (1989) salientam os múltiplos problemas de conteúdo de tais instrumentos. As críticas dizem respeito ao fato de que a maioria dos questionários e das escalas busca avaliar intenções e opiniões ao invés das práticas concretas. As questões são formuladas genericamente ou na terceira pessoa, favorecendo a "desejabilidade social". Estes aspectos favorecem a que os sujeitos respondam aos itens de forma geral, sem buscar comparações com as práticas reais. Além disso, sabe-se que há pequenos detalhes presentes na elaboração das questões que, se forem desconsiderados, poderão exercer um papel fundamental nas repostas. A mensuração de atitudes, opiniões e preferências é uma tarefa complexa, exigindo atenção aos diversos influentes (Plous, 1993).

Além disso, a maioria dos instrumentos busca entender a percepção dos filhos ou dos pais, mas raramente de ambos, o que reduz a compreensão do fenômeno de forma ampla. Corroborando tal reflexão, Bersabé, Fuentes e Motrico (2001) construíram duas escalas, as quais têm por base instrumentos elaborados previamente - Escala de Afeto, Escala de Normas y Exigencia, Inventory of Parent and Peer Attachment (Armsden \& Greenber, 1987), Questionário de Estilos Parentais (Buri, 1991) e Escala de Avaliação de Estilos Educativos (Palacios, 1994 citado por Bersabé et al., 2001). Os autores tinham como objetivo formular um questionário mais amplo, considerando tanto a perspectiva dos filhos como a dos pais. Foi realizada avaliação psicométrica em tais instrumentos (confiabilidade, validez convergente e validez discriminante). Verificou-se o seguinte: o PAQ apresentou índices de confiabilidade aceitáveis, a análise da validez convergente salientou a mensuração de construtos similares aos obtidos na Escala de Normas e Exigências, e as correlações entre os protótipos de autoridade mostraram-se baixas, indicativo favorável à validez discriminante. Além disso, os resultados sugeriram a baixa concordância entre informações dos pais e dos filhos, ponto que salienta ainda mais a relevância de considerar ambas as perspectivas (Bersabé et al., 2001).

Outro estudo desenvolvido por Reitman e colaboradores (2002) objetivou conceber e validar uma versão do PAQ revisada. Destaca-se que as subescalas referentes às disciplinas autoritária e permissiva apresentaram modestos índices de fidedignidade e de validade convergente.

Partindo desses achados, o presente artigo é um estudo complementar de uma pesquisa mais ampla. ${ }^{3}$ Neste estudo, abordou-se análise fatorial em nossa realidade contextual, ou seja, com adultos jovens universitários brasileiros, de um dos instrumentos utilizados na pesquisa ampliada: o Questionário de Estilos Parentais (Parental Authoritative Questionnaire). Para tal, buscaram-se evidências de validade por meio da verificação da estrutura fatorial do instrumento.

\section{Método}

\section{Participantes}

Participaram desta pesquisa 323 adultos jovens, estudantes de graduação de uma universidade privada de Porto Alegre, no Rio Grande do Sul. A idade média foi de 22,19 (desvio padrão= 3,76); do total da amostra, $50,8 \%$ eram mulheres.

Foram realizadas duas etapas de seleção de amostra. Primeiramente, selecionou-se uma amostra estratificada por setores de formação (filosófico-humanístico, sociojurídico-econômico, biomédico e técnicocientífico). Na seguinte etapa, foi realizada escolha por conveniência com relação aos cursos de graduação de cada setor. Os cursos que participaram desta investigação foram: Letras, Psicologia, Serviço Social, Relações Públicas, Direito, Medicina, Fisioterapia, Engenharias, Informática, Ciências Aeronáuticas e Arquitetura.

\section{Instrumento}

O PAQ busca avaliar os conceitos de Baumrind referentes aos estilos parentais permissivo, autoritário e autorizante (Buri, 1991). É composto por 30 situações hipotéticas referentes às estratégias educacionais utilizadas pelos pais durante a infância de seus filhos. O instrumento é formado por três subescalas, cada uma com dez itens, as quais se referem aos estilos parentais autoritário, autorizante e permissivo. Os filhos respondem em uma escala Likert de cinco pontos, sendo dois pontos referentes à discordância ("discordo totalmente" e "discordo"), um ponto neutro ("não concordo nem discordo") e dois referentes à concordância ("concordo totalmente" e "concordo"). No estudo de Buri (1991), foi feita aplicação do instrumento com relação ao estilo parental da mãe, e outro referente ao estilo parental do pai, ambos com as mesmas questões. Nesta pesquisa, optou-se por utilizar somente um instrumento no que respeita aos pais como um todo.

De acordo com a análise de fidedignidade do

\footnotetext{
3 O estudo mais amplo buscou identificar as possíveis correlações existentes entre os estilos parentais, os estilos atribucionais e o bem-estar psicológico de adultos jovens, estudantes de uma universidade particular de Porto Alegre, RS, Brasil.
} 
PAQ na versão original, foram obtidos os seguintes alfas de Cronbach:

- relacionados aos estilos parentais das mães: 0,75 para estilo permissivo, 0,85 para autoritário e 0,82 para autorizante; - relacionados aos estilos dos pais: 0,74 para estilo permissivo, 0,87 para autoritário e 0,85 para autorizante (Buri, 1991).

No presente estudo, foi feita tradução, tendo em vista ser o original em língua inglesa. O processo de tradução foi desenvolvido por quatro juízes, os quais são psicólogos e têm domínio do idioma inglês, havendo um coeficiente kappa de Cohen de 0,75.

No que tange à análise de conteúdo e análise aparente, o questionário traduzido foi aplicado em 10 adultos jovens universitários, a fim de verificar o entendimento, a adequação dos conteúdos e a formatação das questões. Sendo assim, nos itens em que havia possibilidade de substituição por expressões que melhor descrevessem o conteúdo, realizou-se uma adaptação.

Foi aplicado um questionário piloto em 30 estudantes com as mesmas características da população do estudo. A finalidade dessa aplicação era verificar o tempo de aplicação, o percentual de respostas, o percentual de missing cases, a adequação do vocabulário e consistência interna. Foram obtidos os seguintes índices de alpha de Cronbach: 0,85 para permissivo, 0,88 para autoritário e 0,89 para autorizante.

\section{Coleta de dados e procedimentos éticos}

Os alunos foram convidados a participar da pesquisa durante o período de aula. Após a informação sobre os objetivos do estudo, a apresentação por escrito do Termo de Consentimento Informado - o qual abarcava esclarecimentos sobre anonimato e sigilo - os participantes foram orientados para preencher 0 questionário. Foi garantido o caráter voluntário da participação. A pesquisa teve aprovação do Comitê de Ética em Pesquisa da PUCRS sob número 027/04.

\section{Resultados}

\section{Análise de fidedignidade (consistência interna)}

Na presente pesquisa, a análise de consistência interna, utilizando o teste de alfa de Cronbach, apresentou os seguintes coeficientes: 0,74 para estilo permissivo, 0,85 para autoritário e 0,88 para autorizante. Observa-se que as três subescalas obtiveram um nível satisfatório de fidedignidade, sendo a subescala autorizante a que apresentou o maior nível.

\section{Análise fatorial}

Para a análise fatorial exploratória, foram incluídos os 30 itens do PAQ. Pelo gráfico de sedimentação (scree plot), o qual apresenta a distribuição gráfica dos autovalores e componentes, observa-se a possibilidade de realização da análise fatorial com três fatores (Figura 1).

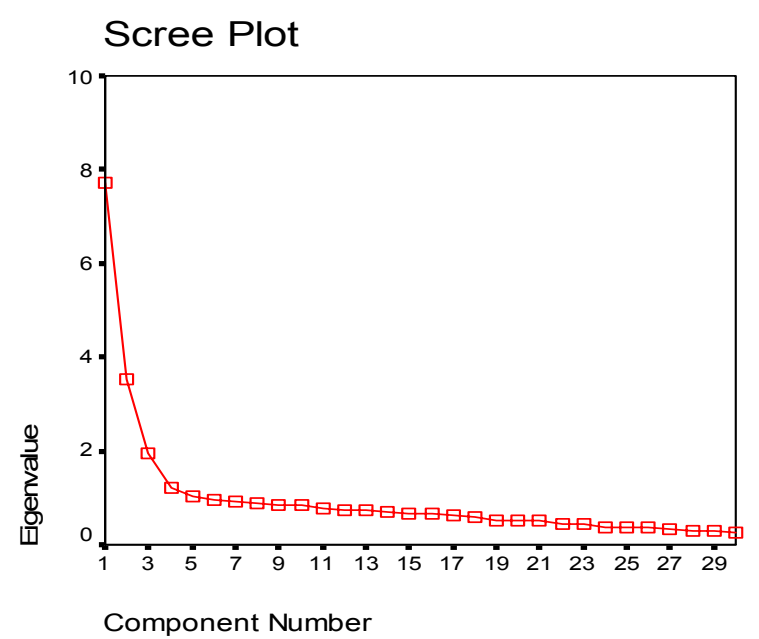

Figura 1 - Gráfico de sedimentação

Além da observação do gráfico de sedimentação, os fatores foram extraídos da análise de componentes principais, com rotação oblimin baseada na resposta de 323 sujeitos. Para tanto, utilizou-se a regra de Kaiser (retenção dos autovalores maiores que 1). A análise demonstrou a presença de três fatores com auto-valores superiores a 1,94 , os quais serão considerados neste estudo. O total dos fatores explica $43,96 \%$ da variância total das respostas dos adultos jovens universitários. $\mathrm{O}$ primeiro fator explica $25,70 \%$, o segundo, $11,77 \%$, e o terceiro, 6,49\% (Tabela 1).

Tabela 1 - Variância total explicada para três fatores

\begin{tabular}{ccccc}
\hline & \multicolumn{2}{c}{ Autovalores iniciais } & \multicolumn{2}{c}{ Soma das saturações ao quadrado da rotação } \\
\hline Componente & Total & \% da variância & \% acumulado & Total \\
1 & 7,710 & 25,700 & 25,700 & 6,548 \\
2 & 3,531 & 11,771 & 37,471 & 3,342 \\
3 & 1,949 & 6,495 & 43,966 & 5,554 \\
\hline
\end{tabular}

Método de extração: Análise de componentes principais. 
Os critérios de seleção de um item para um determinado fator foram: ter carga fatorial superior ou igual a 0,40 (positiva ou negativa) na pattern matrix, sendo este nível bastante significativo, e ter congruência semântica com os demais itens que compõem o fator.

Nas Tabelas 2, 3 e 4 estão descritos os valores dos três fatores e as comunalidades.

Tabela 2 - Carga fatorial, comunalidades $\left(h^{2}\right)$, percentual da variância, autovalores e alfas de Cronbach referentes ao fator 1 - estilo parental autorizante

\begin{tabular}{|c|c|c|}
\hline Item & $\begin{array}{c}\text { Fator } 1 \\
\text { Autorizante }\end{array}$ & $\mathrm{h}^{2}$ \\
\hline $\begin{array}{l}\text { 4. Quando uma regra familiar era estabelecida, meus pais explicavam os motivos desta para } \\
\text { os filhos. }\end{array}$ & 0,696 & 0,496 \\
\hline $\begin{array}{l}\text { 5. Meus pais encorajavam o diálogo quando eu sentia que as regras e restrições familiares } \\
\text { não estavam de acordo com o que eu pensava. }\end{array}$ & 0,740 & 0,597 \\
\hline 8. Meus pais orientavam os filhos na minha família através do diálogo e da disciplina. & 0,712 & 0,515 \\
\hline $\begin{array}{l}\text { 11. Eu sabia o que meus pais esperavam de mim, mas eu também me sentia livre para } \\
\text { conversar quando eu não concordava. }\end{array}$ & 0,675 & 0,483 \\
\hline 15. Meus pais davam orientações de forma clara e consistente. & 0,702 & 0,518 \\
\hline $\begin{array}{l}\text { 20. Meus pais levavam em consideração a opinião dos filhos nas decisões familiares, mas } \\
\text { não tomavam decisões simplesmente porque os filhos queriam. }\end{array}$ & 0,570 & 0,339 \\
\hline $\begin{array}{l}\text { 22. Meus pais tinham padrões bem definidos de comportamento para os filhos, mas eles } \\
\text { estavam dispostos a ajustar esses padrões às necessidades individuais de cada um. }\end{array}$ & 0,630 & 0,411 \\
\hline $\begin{array}{l}\text { 23. Meus pais orientavam meu comportamento e esperavam que eu seguisse as suas } \\
\text { orientações, mas sempre ouviam as minhas opiniões e conversavam comigo. }\end{array}$ & 0,822 & 0,678 \\
\hline $\begin{array}{l}\text { 27. Meus pais me davam direções claras para os meus comportamentos e para as minhas } \\
\text { atividades, mas também eram compreensivos quando eu discordava daquelas. }\end{array}$ & 0,627 & 0,414 \\
\hline $\begin{array}{l}\text { 30. Se meus pais tomassem uma decisão que me magoasse, eles estavam dispostos a } \\
\text { conversar comigo e admitir as suas falhas. }\end{array}$ & 0,727 & 0,616 \\
\hline Percentual de variância & 25,700 & \\
\hline Autovalores & 7,710 & \\
\hline Coeficiente alfa de Cronbach & 0,88 & \\
\hline
\end{tabular}

Os itens que compõem o primeiro fator se referem ao estilo parental autorizante (Tabela 2). Pode-se observar que dos 10 itens que compõem este fator, todos os valores são maiores que 0,50 , aspecto que possibilita o aumento da carga do fator. Percebe-se que os itens $23,5,30$ e 8 do instrumento são os que têm maiores valores, todos acima de 0,71 . Já o item 20 é o que tem menor valor $(0,57)$.

O segundo fator é composto por 10 itens e refere-se ao estilo parental permissivo (Tabela 3). É possível identificar que todos os valores estão acima de
0,40, destacando também a carga deste fator. Nota-se que os itens 6 e 19 têm os valores maiores que 0,66. Já o item 24 do questionário é o que tem o menor valor $(0,43)$.

Por fim, o terceiro fator é composto por itens referentes ao estilo parental autoritário (Tabela 4). Os valores desses fatores se encontram acima de 0,50 , aspecto que, como os outros fatores descritos anteriormente, intensifica a carga do fator. Percebe-se que os itens 25 e 9 têm os maiores valores do fator 3 , já que se encontram acima de 0,70 . No entanto, o item 2 do questionário tem o valor mais inferior do fator $(0,54)$. 
Tabela 3 - Carga fatorial, comunalidades $\left(h^{2}\right)$, percentual da variância, autovalores e alfas de Cronbach referentes ao fator 2 - estilo parental permissivo

\begin{tabular}{|c|c|c|}
\hline$\overline{\text { Item }}$ & $\begin{array}{c}\text { Fator } 2 \\
\text { Permissivo }\end{array}$ & $\overline{h^{2}}$ \\
\hline $\begin{array}{l}\text { 1. Meus pais acreditavam que em uma família bem estruturada as crianças deveriam fazer as } \\
\text { coisas do seu próprio jeito, como quisessem. }\end{array}$ & 0,646 & 0,425 \\
\hline $\begin{array}{l}\text { 6. Meus pais acreditavam que uma criança necessita ser livre para tomar suas próprias } \\
\text { decisões e fazer o que quisesse, mesmo que isso não estivesse de acordo com o desejo deles. }\end{array}$ & 0,690 & 0,490 \\
\hline $\begin{array}{l}\text { 10. Meus pais achavam que eu não precisava obedecer às regras e normas de compor- } \\
\text { tamento simplesmente porque alguém com autoridade havia estabelecido. }\end{array}$ & 0,477 & 0,242 \\
\hline 13. Meus pais raramente davam orientações sobre o meu comportamento. & 0,503 & 0,372 \\
\hline $\begin{array}{l}\text { 14. Quando eram estabelecidas as decisões familiares, na maioria das vezes, meus pais } \\
\text { faziam o que os filhos queriam. }\end{array}$ & 0,600 & 0,366 \\
\hline $\begin{array}{l}\text { 17. Meus pais acreditavam que a maior parte dos problemas na sociedade seria resolvida se os pais } \\
\text { não restringissem as atividades, as decisões e os desejos dos filhos durante o seu crescimento. }\end{array}$ & 0,479 & 0,235 \\
\hline $\begin{array}{l}\text { 19. Meus pais me permitiam decidir a maior parte das coisas sozinho sem me dar muitas } \\
\text { orientações. }\end{array}$ & 0,668 & 0,472 \\
\hline 21. Meus pais não se sentiam responsáveis por orientar e dirigir o meu comportamento. & 0,519 & 0,322 \\
\hline $\begin{array}{l}\text { 24. Meus pais permitiam que eu tivesse o meu próprio ponto de vista nos assuntos } \\
\text { familiares e não davam importância se eu decidisse por mim mesmo(a) o que eu iria fazer. }\end{array}$ & 0,434 & 0,199 \\
\hline $\begin{array}{l}\text { 28. Meus pais não davam orientações com relação aos comportamentos, às atividades e aos } \\
\text { desejos dos filhos na minha família. }\end{array}$ & 0,483 & 0,429 \\
\hline Percentual de variância & 11,771 & \\
\hline Autovalores & 3,531 & \\
\hline Coeficiente alfa de Cronbach & 0,74 & \\
\hline
\end{tabular}

Tabela 4 - Carga fatorial, comunalidades $\left(h^{2}\right)$, percentual da variância, autovalores e alfas de Cronbach referentes ao fator 3 - estilo parental autoritário

\begin{tabular}{|c|c|c|}
\hline$\overline{\text { Item }}$ & \begin{tabular}{c|} 
Fator 3 \\
Autoritário
\end{tabular} & $\mathrm{h}^{2}$ \\
\hline $\begin{array}{l}\text { 2. Meus pais me obrigavam a fazer as coisas que eles acreditavam ser correto, mesmo que eu } \\
\text { não concordasse. }\end{array}$ & 0,546 & 0,330 \\
\hline $\begin{array}{l}\text { 3. Sempre que meus pais me diziam para fazer algo, eles esperavam que eu fizesse imedia- } \\
\text { tamente sem questionamentos. }\end{array}$ & 0,635 & 0,407 \\
\hline 7. Meus pais não me permitiam questionar nenhuma de suas decisões. & 0,625 & 0,500 \\
\hline $\begin{array}{l}\text { 9.Meus pais pensavam que deveriam usar a sua autoridade para conseguir que os filhos se } \\
\text { comportassem como deveriam. }\end{array}$ & 0,716 & 0,531 \\
\hline $\begin{array}{l}\text { 12. Meus pais acreditavam que pais sábios deveriam ensinar desde cedo aos filhos quem é o } \\
\text { chefe da família. }\end{array}$ & 0,615 & 0,405 \\
\hline 16. Meus pais ficavam muito chateados se eu tentasse discordar deles. & 0,609 & 0,442 \\
\hline $\begin{array}{l}\text { 18. Meus pais deixavam claro o comportamento que esperavam de mim e, quando eu não } \\
\text { correspondia às suas expectativas, me puniam. }\end{array}$ & 0,693 & 0,481 \\
\hline $\begin{array}{l}\text { 25. Meus pais sempre pensaram que a maioria dos problemas na sociedade seria resolvida se } \\
\text { os pais fossem rígidos e autoritários com os seus filhos. }\end{array}$ & 0,720 & 0,558 \\
\hline 26. Meus pais sempre me diziam exatamente o que fazer e como fazer. & 0,680 & 0,469 \\
\hline $\begin{array}{l}\text { 29. Eu sabia o que meus pais esperavam de mim, e eles insistiam para que eu atendesse às } \\
\text { suas expectativas simplesmente por respeito a sua autoridade. }\end{array}$ & 0,618 & 0,449 \\
\hline Percentual de variância & 6,495 & \\
\hline Autovalores & 1,949 & \\
\hline Coeficiente de alfa de Cronbach & 0,85 & \\
\hline
\end{tabular}


A fim de entender como esses três fatores se comportam quando aplicados conjuntamente, realizouse uma matriz correlacional com os fatores (Tabela 5).
Foi utilizada a Análise dos Componentes Principais como método de extração e o método oblimin com normalização Kaiser como método de rotação.

Tabela 5 - Correlação entre fatores

\begin{tabular}{l|ccc}
\hline & $\begin{array}{c}\text { Fator 1 } \\
\text { Autorizante }\end{array}$ & $\begin{array}{c}\text { Fator 2 } \\
\text { Permissivo }\end{array}$ & $\begin{array}{c}\text { Fator 3 } \\
\text { Autoritário }\end{array}$ \\
\hline Fator 1- Autorizante & 1 & $-0,106$ & $-0,588^{* *}$ \\
Fator 2 - Permissivo & $-0,106$ & 1 & $-0,068$ \\
Fator 3 - Autoritário & $-0,588^{* *}$ & $-0,068$ & 1 \\
\hline
\end{tabular}

** Correlação é significante no nível de 0,01 (2-tailed).

Os resultados descritos demonstram as correlações existentes entre os três fatores. $O$ fator 1 , o qual diz respeito ao estilo parental autorizante, apresentou-se inversamente correlacionado com o fator 3 , o qual é referente ao estilo parental autoritário $(r=-0,588$, $p<0,01)$. Já o fator 2 - estilo parental permissivo - não apresentou correlação significativa com os fatores 1 e 3 , aspecto que representa a independência desse fator.

\section{Discussão}

A interpretação dos fatores foi realizada partindo da análise dos itens que mais intensificam a consistência de cada fator (Tabela 2, 3 e 4). Foi analisada também a análise das correlações entre os fatores (Tabela 5).

No primeiro fator, o qual diz respeito ao estilo parental autorizante, percebemos que os itens de maior carga se referem explicitamente à possibilidade de diálogo entre pais e filhos (itens 23, 5, 30 e 8) (Tabela 2). Estes itens corroboram a definição dessa estratégia educacional, já que, de acordo com Baumrind $(1965,1978)$, pais autorizantes encorajam as verbalizações (p. ex., "Meus pais orientavam os filhos na minha família através do diálogo e da disciplina"). O conteúdo semântico desses itens intensifica a relação existente entre a teoria e o estilo parental. Já o item com menor carga (20) tem conteúdo distinto, faz alusão à questão de que os pais não são orientados em suas estratégias somente devido ao desejo dos filhos. Este último item, além de trazer temática distinta à possibilidade de diálogo, encontra-se formulado partindo da negativa do estilo parental permissivo, aspecto que pode ter suscitado outras reflexões e percepções.

O segundo fator refere-se ao estilo parental permissivo (Tabela 3). Ele se caracteriza por uma postura parental afirmativa, orientada pela aceitação dos pais para com os filhos. Como já se expôs anteriormente, os pais enxergam a si como um recurso para a criança utilizar somente se for de seu desejo (Baumrind, 1965, 1978, 1996). O conteúdo dos itens com elevados níveis de carga (6 e 19) refere-se à possibilidade de a criança ter liberdade na tomada de decisão de suas Psico-USF, v. 10, n. 1, p. 1-9, jan./jun. 2005 ações, prevalecendo o seu desejo ao dos cuidadores, sendo consistente com a definição de Baumrind (p. ex., "Meus pais me permitiam decidir a maior parte das coisas sozinho sem me dar muitas orientações"). No entanto, o item 24, o qual apresentou menor valor, aponta também o conteúdo semântico referente à liberdade na tomada de decisão, mas a questão foi elaborada partindo do conteúdo negativo ("não davam importância se eu decidisse por mim mesmo...”), podendo ter influído na resposta, pois se sabe que existem variáveis presentes na formulação das questões que podem influenciar de forma surpreendente as repostas (Plous, 1993).

O último fator é referente ao estilo parental autoritário. Destacando os itens 25 e 9, pode-se considerar a existência, nesses itens, da palavra "autoridade", aludindo esta a uma estratégia dos pais para a solução dos problemas (Tabela 4). Além disso, esses itens se referem à percepção dos pais com relação ao que acreditavam ser melhor para os filhos ("meus pais pensavam que..." e "meus pais sempre pensaram que a maioria...."). O conteúdo desses itens vai ao encontro da definição proposta por Baumrind para o estilo autoritário, a qual salienta a obediência dos filhos para com os pais, partindo sempre da percepção de que a opinião e a orientação dos pais é a única a ser considerada (Baumrind, 1978). Já o item com menor carga alude a uma atitude dos filhos ("meus pais me obrigavam...”) como conseqüência da estratégia dos pais, diferenciando-se dos itens 25 e 9, pois no conteúdo desses itens não há claramente uma atitude dos filhos, mas sim a percepção dos pais.

No que respeita à análise correlacional dos fatores, foi possível perceber que o fator 3 (estilo parental autoritário) apresentou-se inversamente correlacionado com o fator 1 (estilo parental autorizante), demonstrando a interdependência existente entre tais fatores. Esses achados corroboram o estudo de Buri (1991), já que estes mesmos fatores se apresentaram correlacionados negativamente. Pode-se justificar que a presença, no questionário, dos itens referentes ao estilo parental autoritário, facilita a clareza do entendimento dos itens 
específicos ao estilo parental autorizante e vice-versa. Já o fator que apresentou maior autonomia foi o 2 - estilo parental permissivo -, não estando correlacionado com nenhum dos outros dois fatores. O conteúdo referente ao estilo parental permissivo é inverso ao conteúdo referente ao estilo parental autoritário, o que pode suscitar reflexões acerca da inexistência de correlação com este. Já o estilo autorizante refere-se à idéia de que o cuidador não precisa decidir entre uma disciplina autoritária e permissiva, podendo alternar suas atitudes entre as duas contribuições. $\mathrm{O}$ estilo autorizante seria o caminho do meio entre o permissivo e autoritário. Além disso, considerando a menção de Baumrind $(1965,1978)$ no que tange ao controle, afeto e apoio como importantes funções parentais que perpassam os estilos, há carência dessas funções no estilo permissivo; há integração e sinergia delas no estilo autorizante; e há sua presença de forma veemente no autoritário. Quando aparecem essas funções, percebe-se sua correlação. No entanto, quando há carência, pode-se pensar em maior diferenciação e, conseqüentemente, maior autonomia do fator. Esses achados salientam a necessidade da elaboração de outros estudos que possibilitem maior diferenciação entre todos os fatores.

\section{Considerações gerais}

A análise fatorial do Questionário de Estilos Parentais (PAQ) possibilitou a identificação dos três fatores existentes no instrumento, os quais explicam $43,96 \%$ da variância total encontrada. O primeiro fator, referente ao estilo parental autorizante, explica $25,7 \%$ da variância; já o segundo, o qual diz respeito ao estilo parental permissivo, explica $11,77 \%$. O último, que faz menção ao estilo parental autoritário, explica $6,49 \%$ da variância. Sendo assim, foi possível verificar que o instrumento tem uma estrutura fatorial consistente.

Os fatores identificados salientam a identificação com os pressupostos teóricos de Baumrind (1965, 1978, 1996), teoria na qual Buri (1991), o autor original do questionário, se baseou para formulação das questões.

O PAQ revelou ser um questionário com dimensões bem definidas. Os itens que compunham cada fator ratificaram diretamente os itens identificados pelo autor do artigo original, quando este estabeleceu os itens indicativos para cada estilo (Buri, 1991).

A análise desenvolvida neste estudo salienta a importância de pesquisas relativas a amostras referentes a adultos jovens, já que nos deparamos, na literatura vigente, com múltiplos estudos concernentes a amostras de adolescentes. Assim, o presente trabalho encontra, também, sua relevância na amostra escolhida. Ao mesmo tempo, os resultados alcançados sugerem a necessidade de novas investigações que possibilitem validar o instrumento em amostras diversificadas para a população brasileira. Da mesma forma, salienta-se a necessidade da elaboração de estudos em profundidade no que concerne às estratégias educacionais intrafamiliares. Cabe, também, destacar a relevância de futuras investigações que incluam tanto as percepções dos filhos quanto as dos pais.

\section{Referências}

Armsden, G. C. \& Greenber, M. T. (1987). The inventory of parental and peer attachment: Individual differences and their relationship to psychological well-being in adolescence. Journal of Youth and Adolescence, 16, 427-454.

Baumrind, D. (1965). Parental control and parental love. Children, 12(6), 230-234.

Baumrind, D. (1971). Harmonious parents and their preschool children. Developmental Psychology, 4(1), 99-102.

Baumrind, D. (1978). Parental disciplinary patterns and social competence in children. Youth \& Society, 9(1), 239-275.

Baumrind, D. (1980). New directions in socialization research. American Psychologist, 9, 293-306.

Baumrind, D. (1996). The discipline controversy revisited. Family Relations, 5, 405-413.

Belsky, J. (1984). The determinants of parenting: A process model. Child Development, 55, 83-96.

Bersabé, R., Fuentes, M. J. \& Motrico, E. (2001). Analisis psicométrico de dos escalas para evaluar estilos educativos parentales. Psicothema, 13(4), 678-684.

Buri, J. R. (1991). Parental Authority Questionnaire. Journal of Personality Assessment, 57(1), 110-119.

Buri, J. R., Murphy, P., Richtsmeier, L. M. \& Komar, K. K. (1988). Stability of parental nurturance as a salient predictor of self-esteem. Psychological Reports, 71(2), 535-543.

Costa, F. T., Gomes, W. B. \& Teixeira, M. A. P. (2000). Responsividade e exigência: dois questionários para avaliar estilos parentais. Psicologia, Reflexão e Crítica, 13(3), 465-473.

Furnham, A. \& Cheng, H. (2000). Perceived parental behavior, self-esteem and happiness. Social Psychiatric Epidemiology, 35(10), 463-470.

Gonzales, A., Greenwood, G. \& WenHsu, J. (2001). Undergraduate student's goal orientations and their relationship to perceived parenting styles. College Student Journal, 35(2), 182-192. 
Henderson, D. O. (2001). Understanding parenting styles as a preventive construct for adolescents males. Dissertation Abstracts International, 62(3), order number DA 3008835.

Holden, G. \& Edwards, L. (1989). Parental attitudes toward child rearing: Instruments, issues, and implications. Psychological Bulletin, 106, 29-58.

Lai, K. W. \& McBride, C. C. (2001). Suicidal ideation, parenting style, and family climate among Hong Kong adolescents. International Journal of Psychology, 36(2), 81-87.

Lane, S. T. M. (1999). O processo grupal. Em S. T. M. Lane (Org.). Psicologia social: o homem em movimento. (pp. 115-130). São Paulo: Brasiliense.

Melis, F., Dávila, M. A., Ormeño, V., Vera, V., Greppi, C. \& Gloger, S. (2001). Estandarización del PBI, versíon adaptada a la población entre 16-64 años del Gran Santiago. Revista Chilena Neuro-Psiquiatria, 39(2), 132-139.

Minuchin, S. \& Nichols, M. P. (1982). Famílias: funcionamento e tratamento. Porto Alegre: Artes Médicas.

Musito, G. \& Cava, M. J. (2001). La familia y la educación. Barcelona: Octaedro.

Oliveira, E. A., Marin, A. H., Pires, F. B., Frizzo, G. B., Ravanello, T. \& Rossolo, C. (2002). Estilos parentais autoritário e democrático-recíproco intergeracionais, conflito conjugal e comportamentos de externalização e internalização. Psicologia: Reflexão e Crítica, 15(1), 1-11.

Pacheco, J. T. B., Texeira, M. A. P. \& Gomes, W. B. (1999). Estilos parentais e desenvolvimento de habilidades sociais na adolescência. Psicologia: Teoria e pesquisa, 15, 117-126.
Pinderhughes, E. E., Dodge K. A., Bates, J. E., Pettit, G. S. \& Zelli, A. (2000). Discipline responses: Influences of parent's socioeconomic status, ethnicity, beliefs about parenting, stress, and cognitive-emotional process. Journal of Family Psychology, 14(3), 380-400.

Plous, S. (1993). The psychology of judgment and decision making. United States: McGraw-Hill.

Reis, J. R. T. (1999). Família, emoção e ideologia. Em S. T. M. Lane (Org.). Psicologia social: o homem em movimento. (pp. 99-124). São Paulo: Brasiliense.

Reitman, D., Rhode, P. C., Hupp, S. D. A. \& Altobello, C. (2002). Development and validation of the Parental Authority Questionnaire-Revised. Journal of Psychopathology and Behavioral Assessment, 24(2), 119-127.

Reti, I. M., Samuels, J. F., Eaton, W. W., Bienvenu, O. J., Costa Jr., P. T. \& Nestadt, G. (2002). Influences of parenting on normal personality traits. Psychiatry Research, 111, 55-64.

Ruiz, C. \& Esteban, M. (1999). Estilos de educación familiar y estrés. Em J. Buendía (Org.). Familia y Psicología de la Salud. Madrid: Editora Pirámides.

Thompson, M. J. J., Raynor, A., Cornah, D., Stevenson, J. \& Sonuga-Barke, S. (2001). Parenting behavior described by mothers in a general population sample. Child: Care, Health and Development, 28(2), 149-155.

Wintre, M. G. \& Sugar, L. A. (2000). Relationship with parents, personality and universities transition. Journal of College Student Development, 41(2), 202-214.

Recebido em fevereiro de 2005

Reformulado em abril de 2005

Aprovado em junho de 2005

Sobre os autores:

Mariana Gonçalves Boeckel é psicóloga e mestre em Psicologia Social e da Personalidade do Programa de PósGraduação em Psicologia da Pontifícia Universidade Católica do Rio Grande do Sul.

Jorge Castellá Sarriera é psicólogo e psicopedagogo, mestre em Psicologia Escolar (PUCRS), doutor em Psicologia (UAM-Espanha) e professor da Pontifícia Universidade Católica do Rio Grande do Sul. 